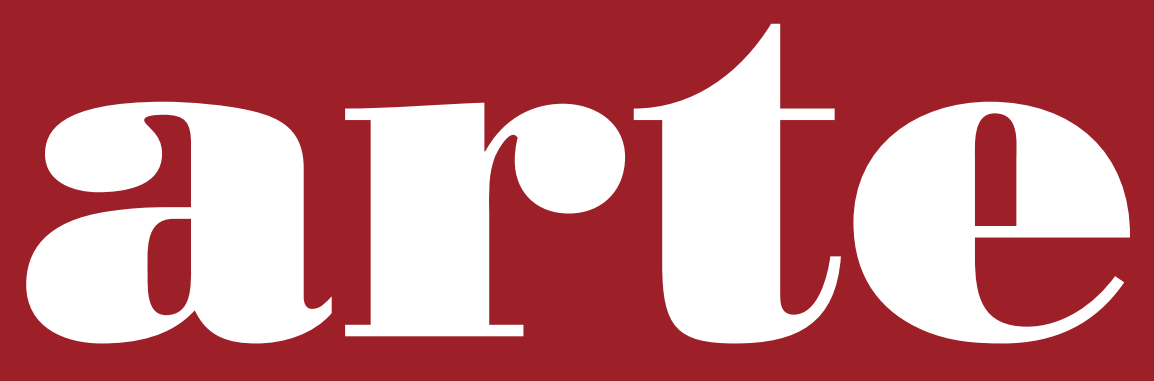




\title{
A arte que resiste ao poder e à violência
}

\author{
Leila Kiyomura
}

Fotos de Atílio Avancini 


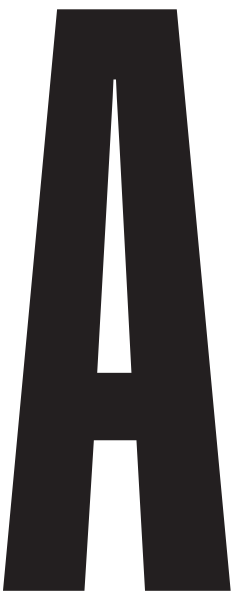

arte de Regina Silveira resiste, provoca. Vai pelo tempo, registrando o golpe militar de 1964, os 21 anos da ditadura e o poder armado de hoje, que se apropria e destoa do verde e amarelo. Porém Regina, também professora da Escola de Comunicações e Artes (ECA) da USP, ensina o infinito das cores em preto-e-branco, sombras e luz, realidade e fantasia, percepção e criatividade. Basta entrar no Museu de Arte Contemporânea (MAC) da USP e peregrinar por sua arte de mais de seis décadas para compartilhar os conflitos e desafios da história do país.

A exposição "Regina Silveira: outros paradoxos" (em cartaz de 28 de agosto de 2021 a 3 de julho de 2022) reúne 180 obras que ocupam o térreo e o primeiro andar do MAC, no Ibirapuera, em São Paulo. Tem a curadoria da diretora do museu, Ana Magalhães, e de Helouise Costa, ambas professoras do Programa de Pós-Graduação Interunidades em Estética e História da Arte (PGEHA) da USP.

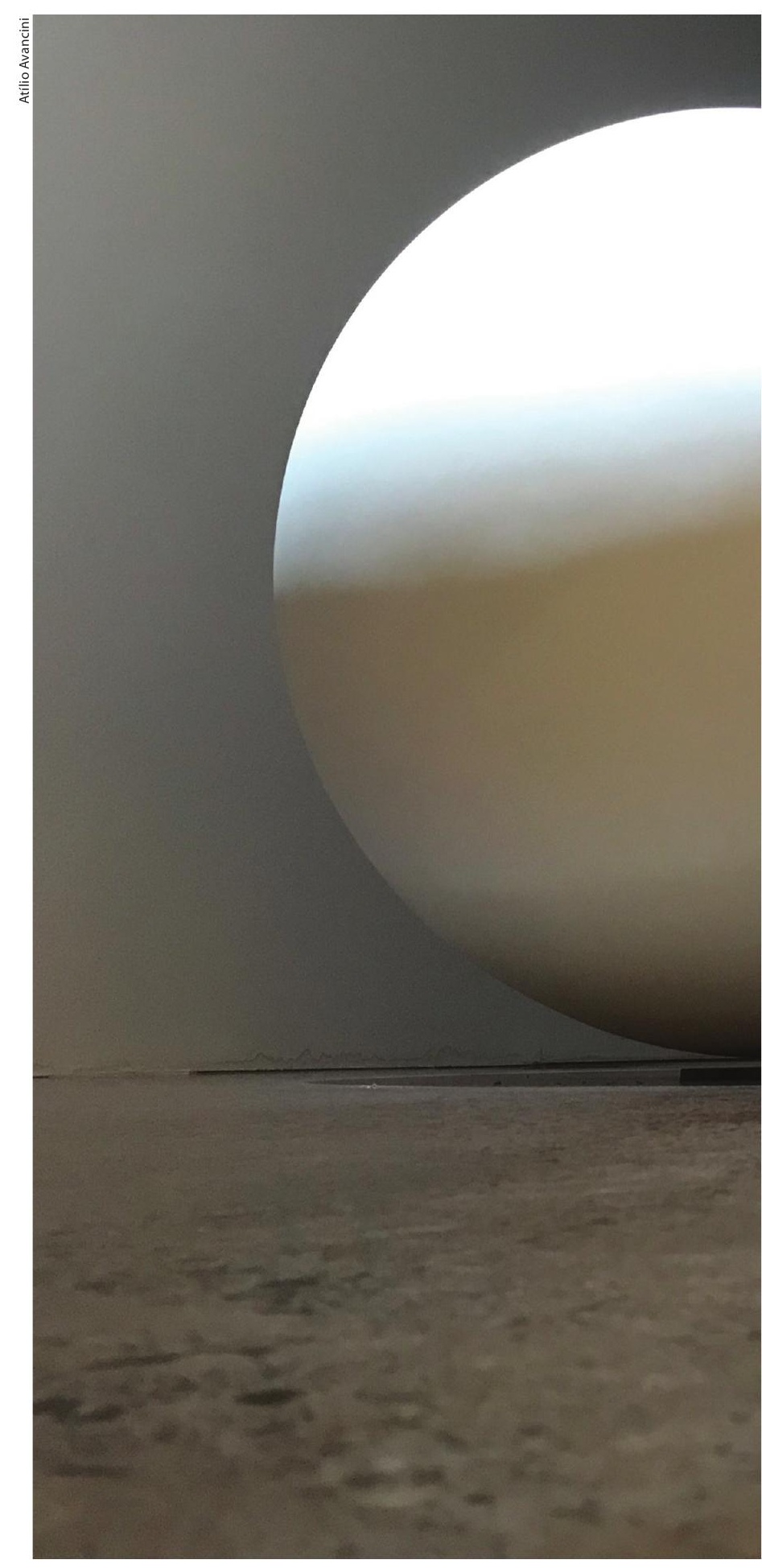

LEILA KIYOMURA é jornalista do Jornal da USP e crítica de arte da Associação Brasileira de Críticos de Arte (ABCA) e da Associação Internacional de Críticos de Arte (Aica). 


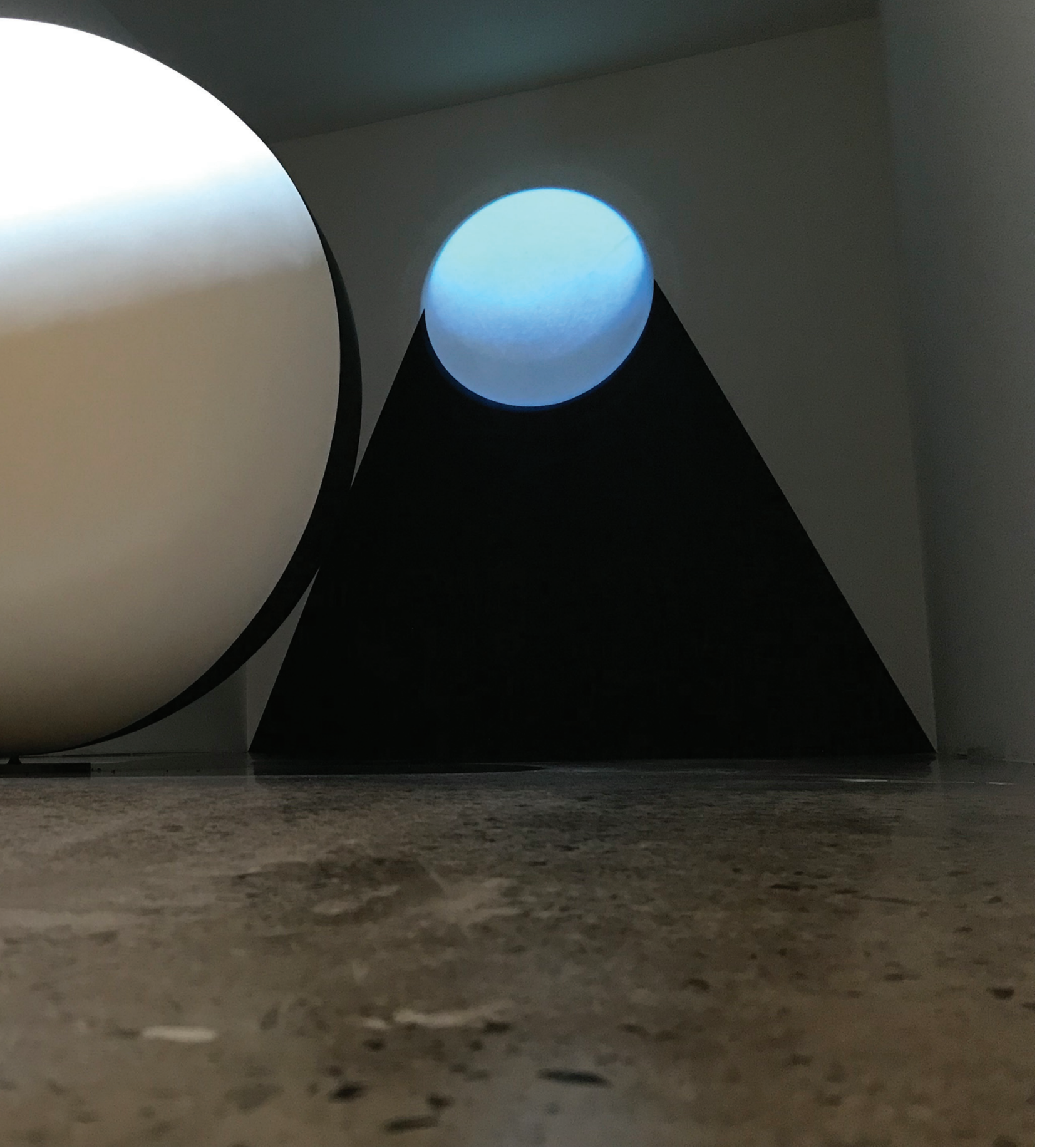

Equinócio, 2002: a artista transforma o modo de percepção do real 


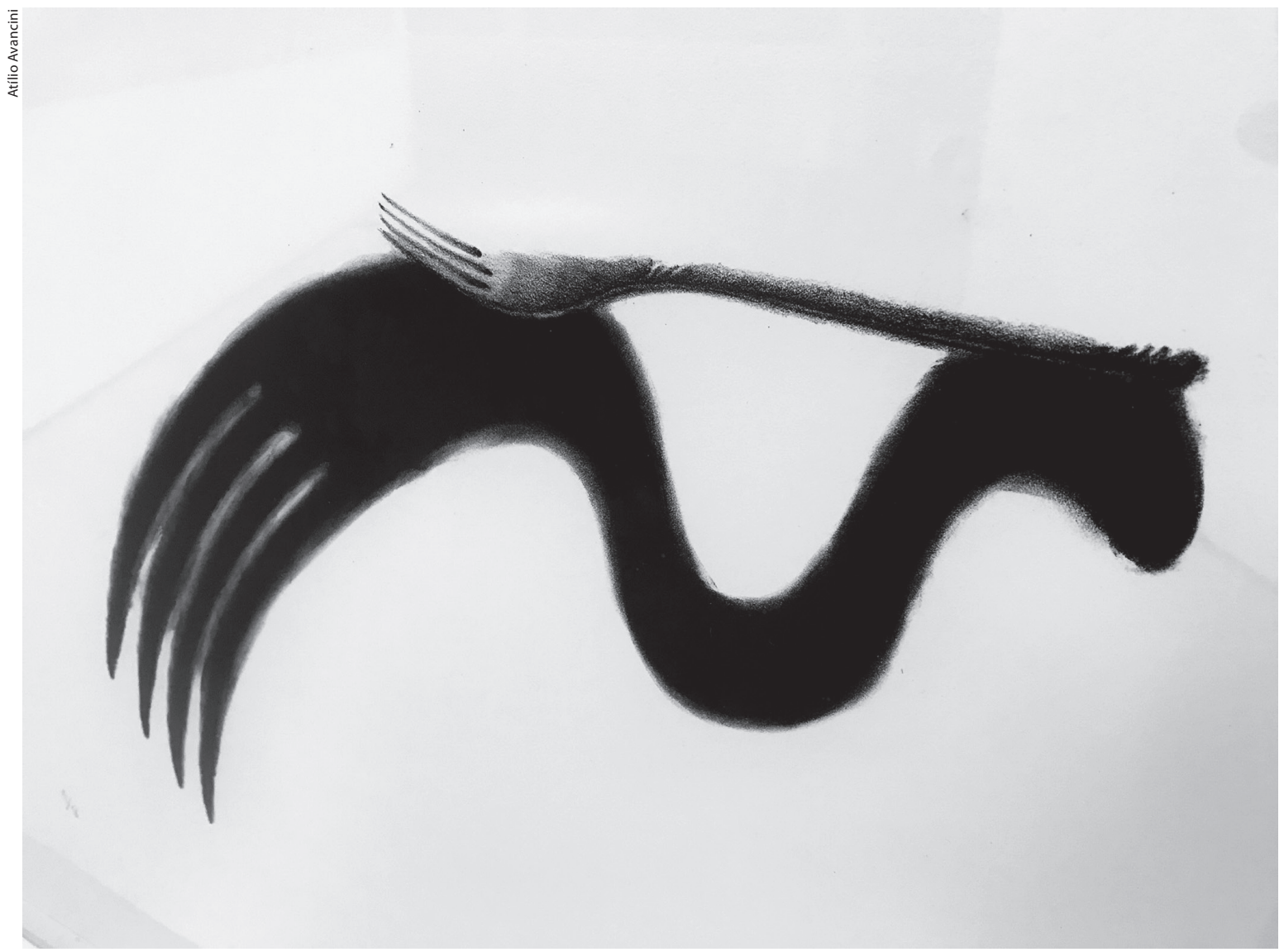

Garfo, smile 6, 1983, litografia sobre papel: retrospectiva no MAC instiga, questiona

"A mostra faz parte da parceria estabelecida entre o MAC e a Fundação Bienal para a 34 Bienal de São Paulo", explica Ana Magalhães. "Esse tipo de parceria foi feito com várias instituições na cidade de São Paulo, que trabalharam em uma exposição monográfica de um artista presente na $34^{\mathrm{a}}$ Bienal. No caso do MAC, o nome de Regina foi sugestão do museu para os curadores da Bienal, que depois desenvolveram com a artista seus projetos para a $34^{\mathrm{a}}$ Bienal em diálogo com a retrospectiva no MAC." Segundo a professora, "o trabalho de pesquisa para a exposição exigiu revisitar a extensa e rica trajetória da artista, que começa com a produção de gravuras nos anos 1960". 


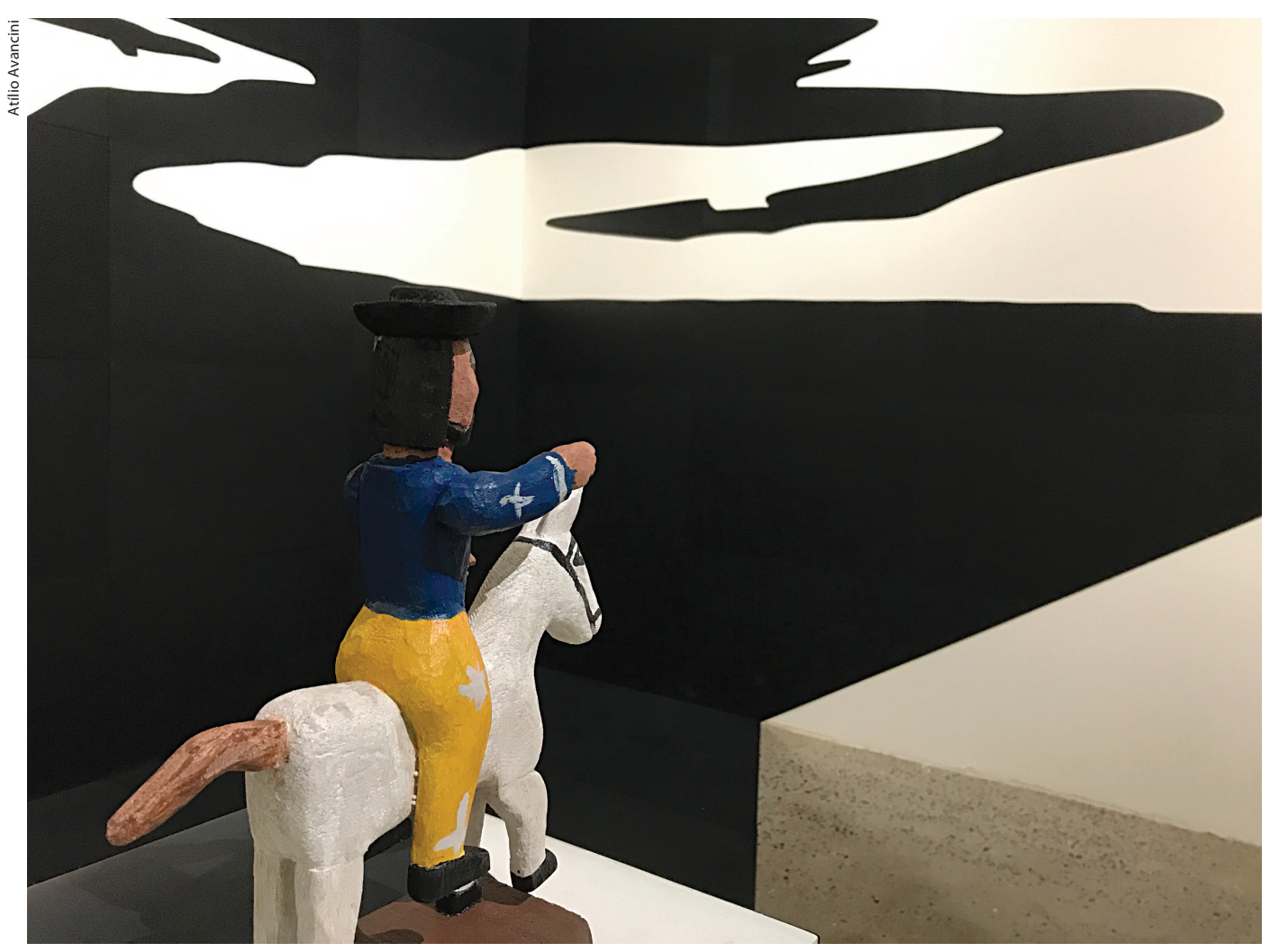

Uma pequena escultura de madeira do patrono militar da América espanhola integra a obra Paradoxo do Santo

O título da mostra, "Regina Silveira: outros paradoxos", é inspirado na obra Paradoxo do santo. Trata-se de uma instalação que o público do MAC já conhece de outras montagens, mas, toda vez que é observada, tem algo novo a dizer. Regina apresentou a obra pela primeira vez no Museo del Barrio, em Nova York, em 1994, e naquele mesmo ano foi doada ao MAC. É uma pequena escultura de madeira do patrono militar da América espanhola, Santiago Apóstolo. A partir dela, a artista criou uma sombra que não corresponde às suas próprias formas. $\mathrm{O}$ visitante se depara com uma imagem distorcida do monumento de Victor Brecheret em homenagem a Duque de Caxias, patrono do Exército brasileiro. Os dois líderes são conectados pela sombra, questionando o espectador sobre algo que vai além da sombra das aparências. 


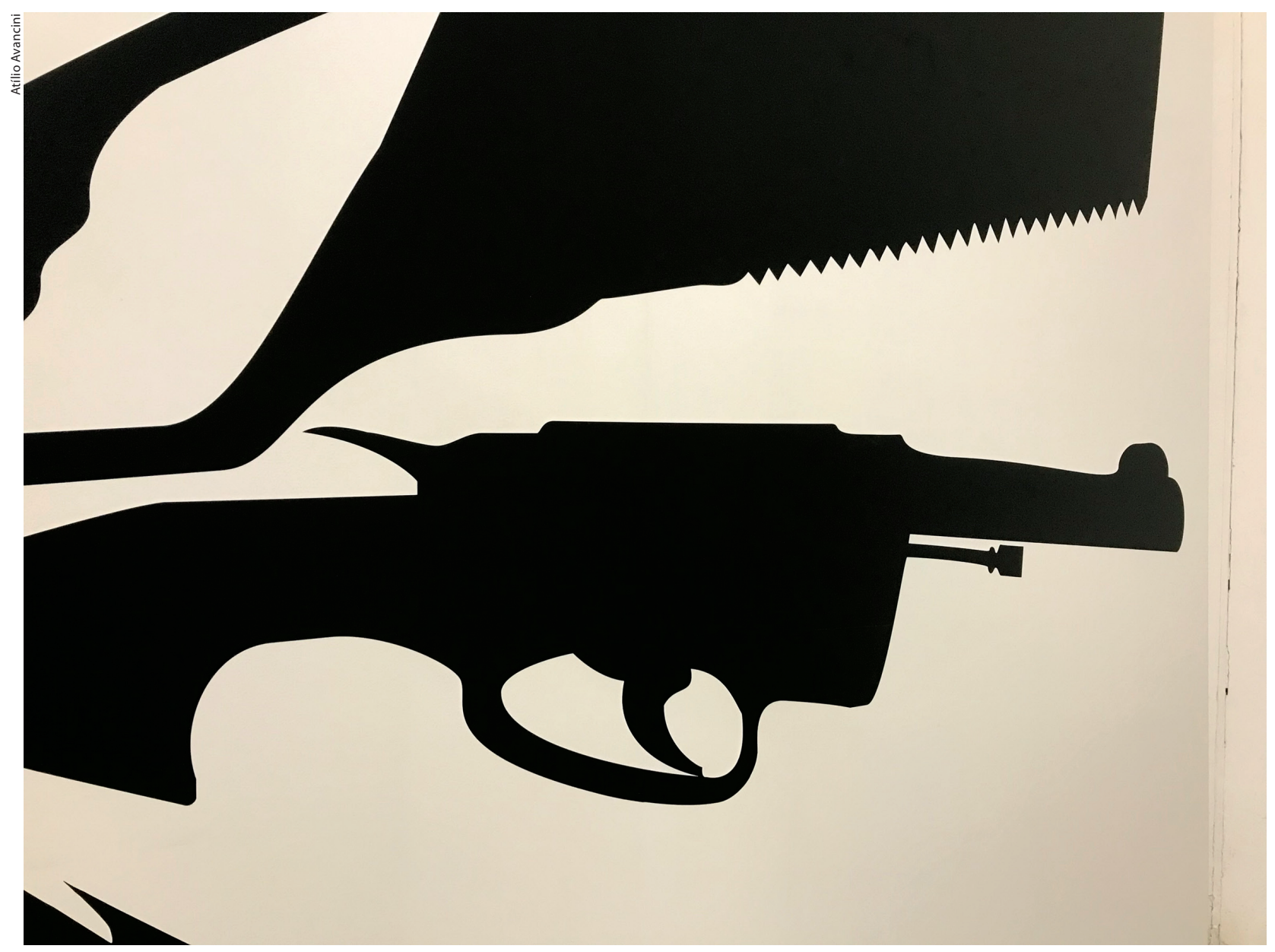

Na mostra, o Brasil da ditadura e o país de hoje

A exposição segue instigando o olhar do público, propondo reflexões sobre temas que envolvem o Brasil e a América Latina. Para realizar essa retrospectiva da vida e da arte de Regina Silveira, Ana Magalhães e Helouise Costa tiveram que fazer uma imersão na sua trajetória de mais de seis décadas. Buscaram a artista, hoje com 82 anos, quando começou a trilhar a arte contemporânea. 


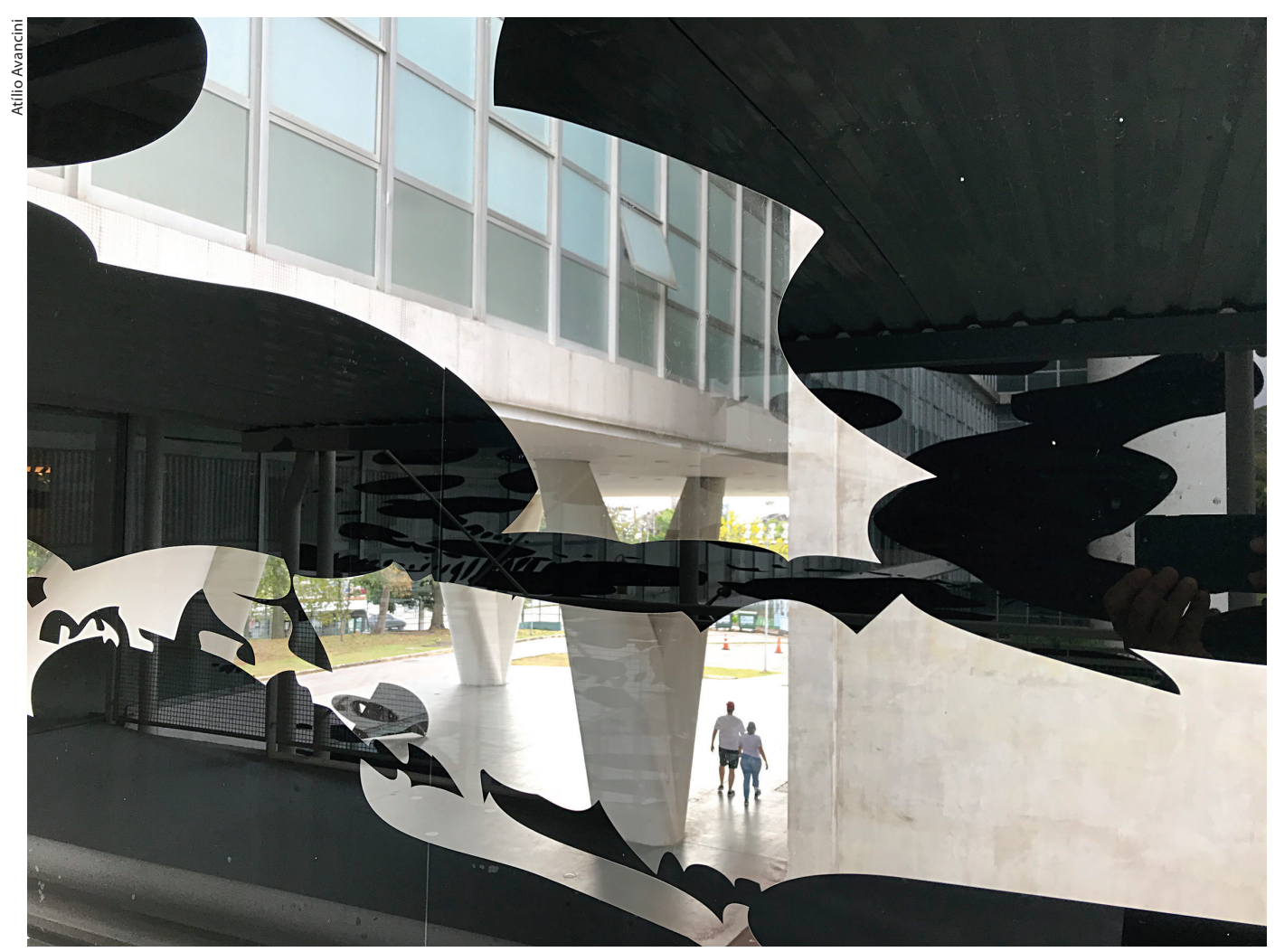

Regina Silveira tem a sua obra impressa nas janelas do MAC

“A mostra começou a ser planejada em 2019, por ocasião da doação de 42 de suas obras ao MAC, que vieram complementar o conjunto que o museu já possuía”, conta Helouise. "O trabalho de pesquisa para a exposição exigiu revisitar a extensa e rica trajetória da artista, que começa com a produção de gravuras nos anos 1960, quando ela era uma jovem recém-formada no Instituto de Artes da Universidade Federal do Rio Grande do Sul (UFRGS), em Porto Alegre. Passa pelas experimentações com apropriação de imagens e videoarte dos anos 1970, abarca propostas de intervenções urbanas e chega a algumas de suas instalações mais recentes. Para dar suporte ao trabalho de curadoria, foi preciso mergulhar nas diferentes fases de sua produção, a fim de compreender as relações entre as obras e a recorrência de certos temas que atravessam sua poética." 


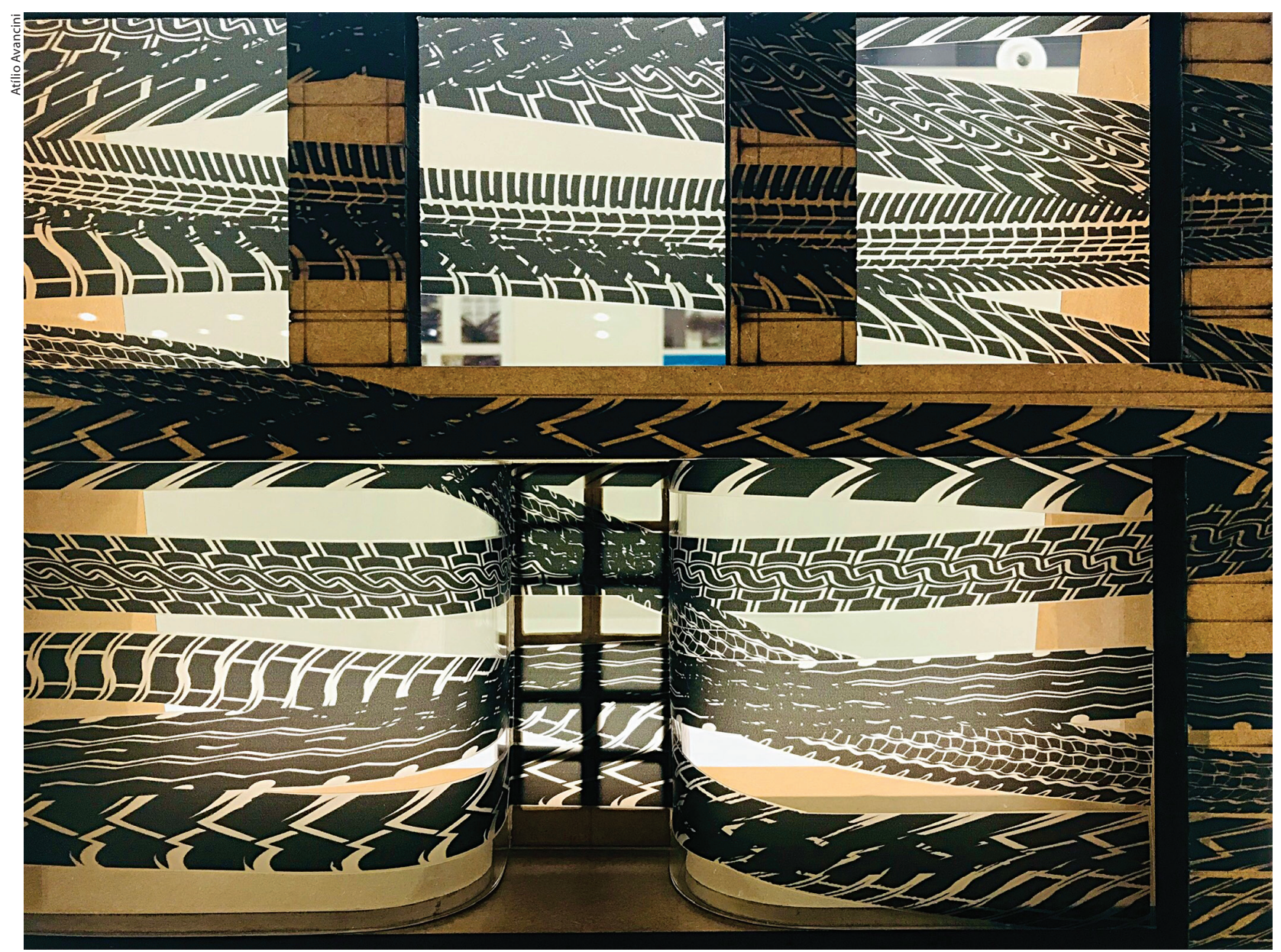

Derrapando, 2009, maquete: rigor estético e precisão técnica

A retrospectiva traz também a história da artista no MAC, desde os anos 1960, sob a direção do professor Walter Zanini. "Foi no MAC que Regina desenvolveu seus primeiros projetos de videoarte, onde ela defendeu o seu doutorado e realizou diversas exposições. Além disso, teve presença ativa no Conselho Deliberativo do museu, como representante dos artistas, durante vários anos. A sua relação com o museu teve início na gestão Zanini, mas se estendeu para além dela", afirma Helouise. 


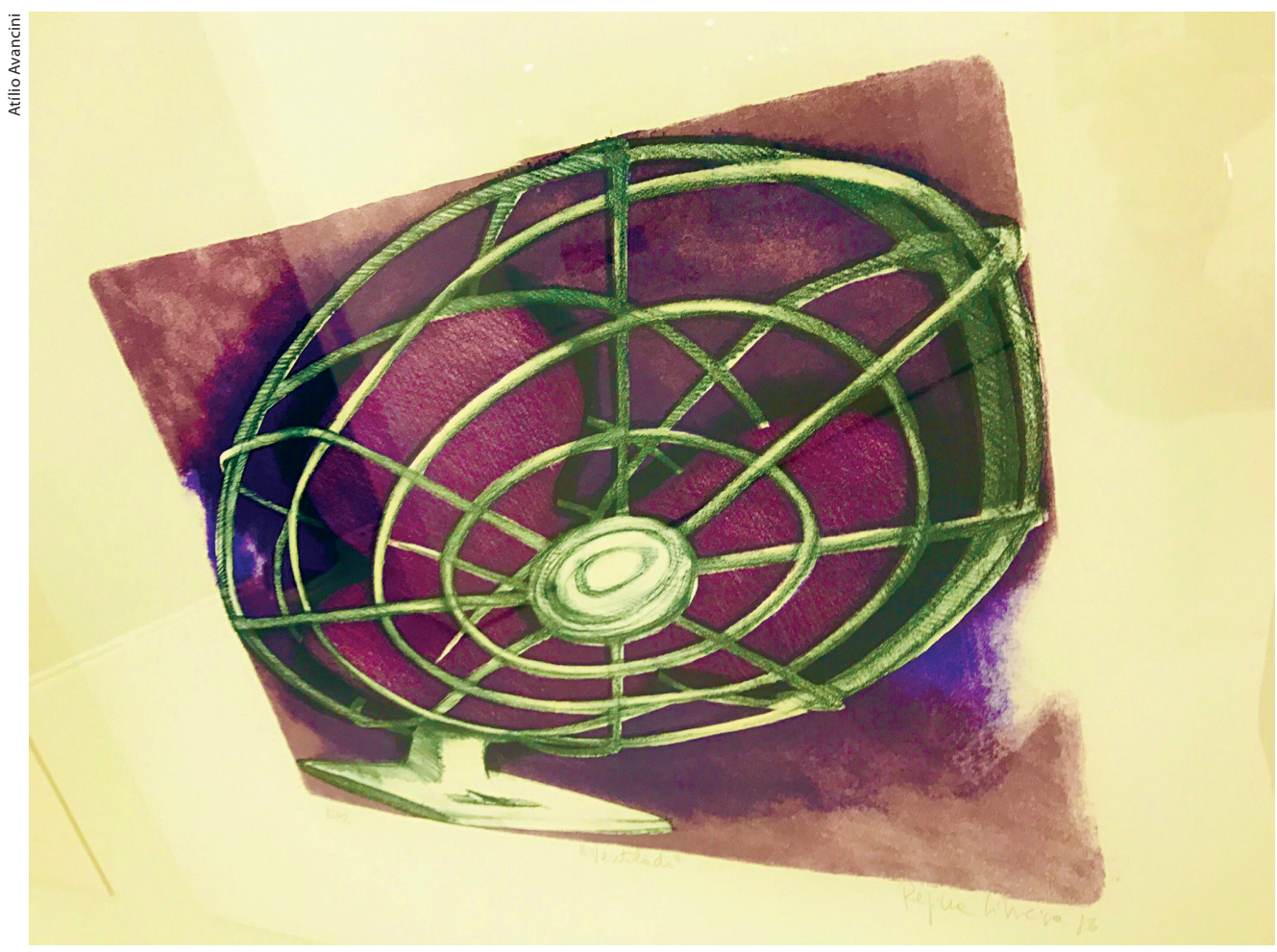

Ventilador, 1986, litografia em cores sobre papel: objetos em perspectiva distorcida

Um "Pudim arte brasileira", com uma pitada de ironia, humor e consciência, é o que Regina Silveira recomenda. A receita está em uma das paredes para quem quiser copiar:

2 xícaras de olhar retrospectivo

1 xícara de ideologia

1 colher, de sopa, da École de Paris

1 lata de definição temática, gelada e sem soro

1 pitada de exacerbação de cor

1 índio, pequeno, ralado

Com o olhar retrospectivo e a ideologia, prepare uma calda e, quando grossa, junte a École de Paris, sem mexer. Deixe amornar, bata um pouco a definição temática, junte os ingredientes e leve ao fogo em banho-maria em forma caramelada.

A receita continua com "cobertura de uma xícara e meia de função social”, e assim por diante. É exatamente esse "pudim", com duas colheres de jogada mercadológica, que, muitas vezes, é servido gelado na arte brasileira. 


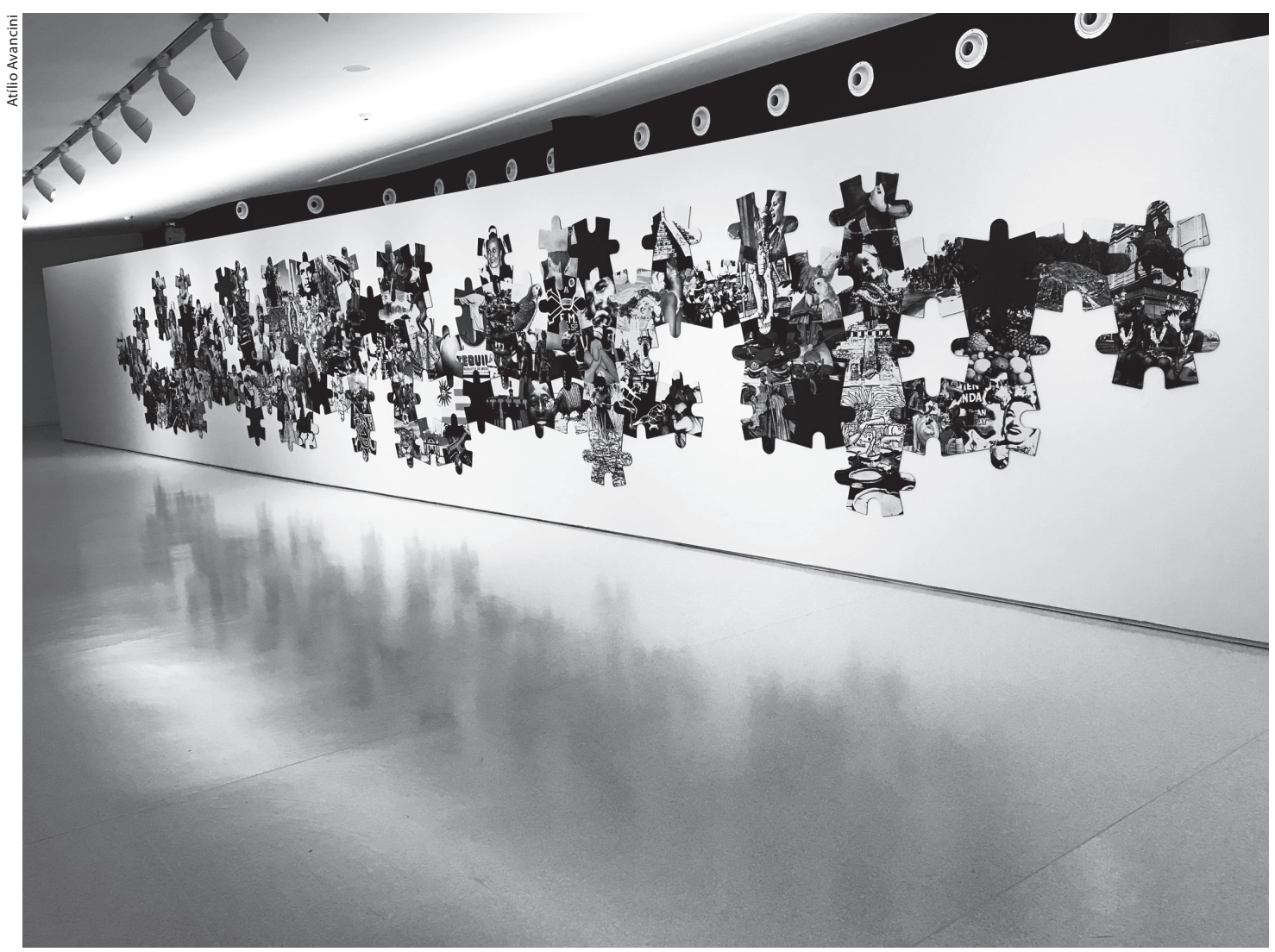

To be continued... (quebra-cabeça da América Latina), obra editada em Nova York, em 1992, atravessa três décadas impactante e atual

No primeiro andar do museu, um mural ocupa toda a parede, compondo um horizonte da nossa realidade política. Uma obra editada em Nova York, em 1992, mas que atravessou três décadas impactante e atual. To be continued... (quebra-cabeça da América Latina) tem como referência os 500 anos da "descoberta" da América. O título dá a ideia de continuidade como nas novelas ou séries, que avisam que novos capítulos estão por vir. Apresenta mais de 100 imagens fotográficas apropriadas de livros, postais e revistas, que mostram os estereótipos da América Latina. A artista aponta, como observam as curadoras, para a fragilidade do conceito de América Latina, revelando as contradições de uma identidade fragmentária construída por um olhar colonialista. 


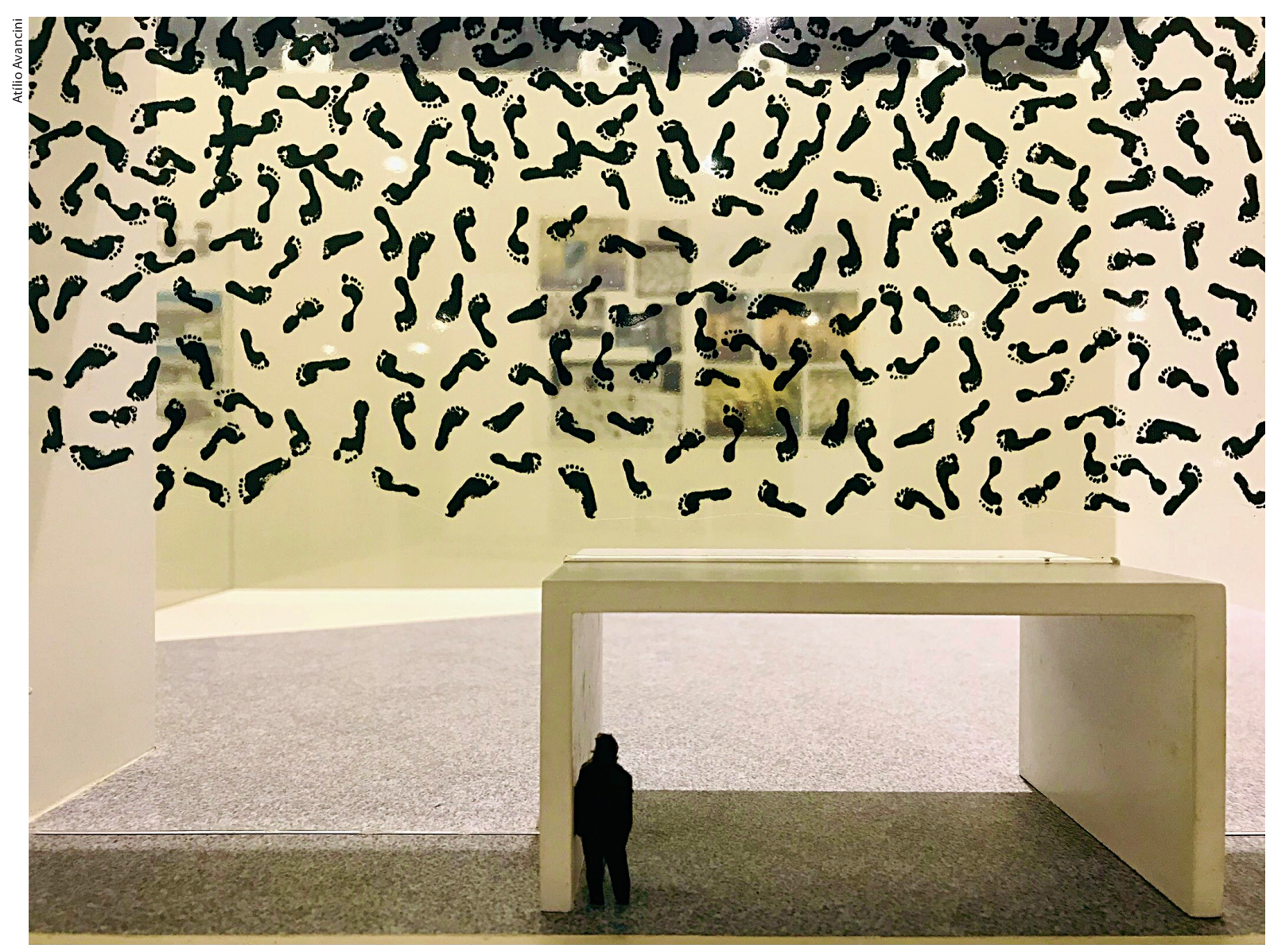

Irruption (Saga), 2006, maquete: exposição com a trajetória de mais de seis décadas

"Regina Silveira problematiza a realidade social de maneira sutil, referindo-se às inúmeras tensões e contradições do país presentes em diversos momentos da nossa história, mas sem referir-se a questões específicas nem assumir uma posição panfletária", destaca Helouise. "A utilização que a artista faz das tecnologias mais recentes em diversos momentos de sua trajetória e dos meios digitais nos últimos anos também fica evidente na exposição, que oferece uma visada histórica sobre tais usos e permite ver como ela adapta seu processo criativo a fim de aproveitar-se de todo o potencial que esses meios têm a oferecer." 


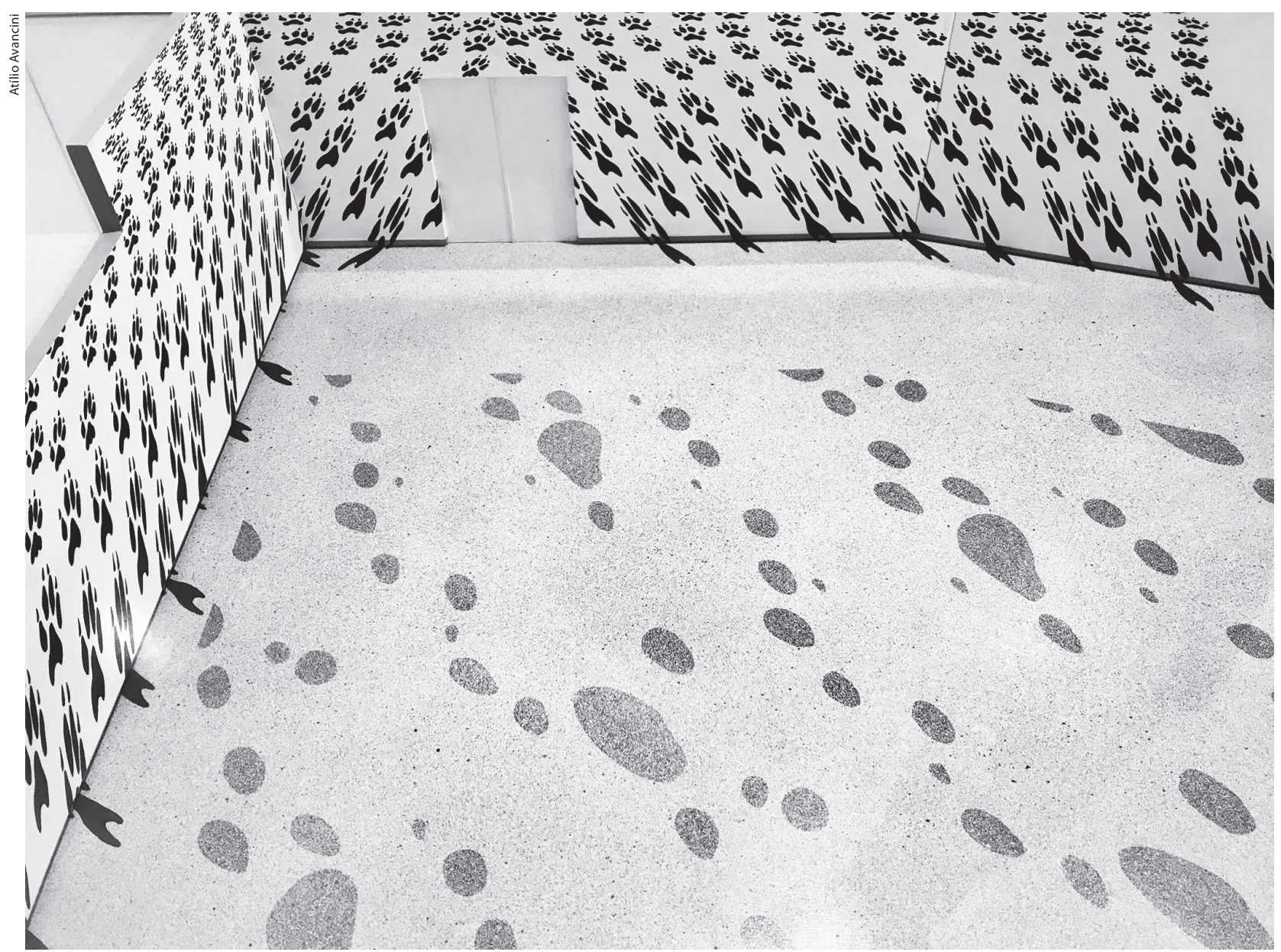

Gone wild, 1996: maquete da pintura sobre parede de $140 \mathrm{~m}^{2}$ no Museu de Arte Contemporânea de San Diego, EUA

"Regina Silveira: outros paradoxos" traduz também o papel do Museu de Arte Contemporânea da USP. "O MAC sempre foi espaço de autonomia de pensamento, de liberdade de expressão e defensor de uma sociedade democrática, respeitosa de suas instituições e sua constituição", afirma a diretora Ana Magalhães. "Nosso papel, como museu universitário, é ser um espaço de formação para a reflexão crítica e de debate sobre as questões candentes da contemporaneidade." 


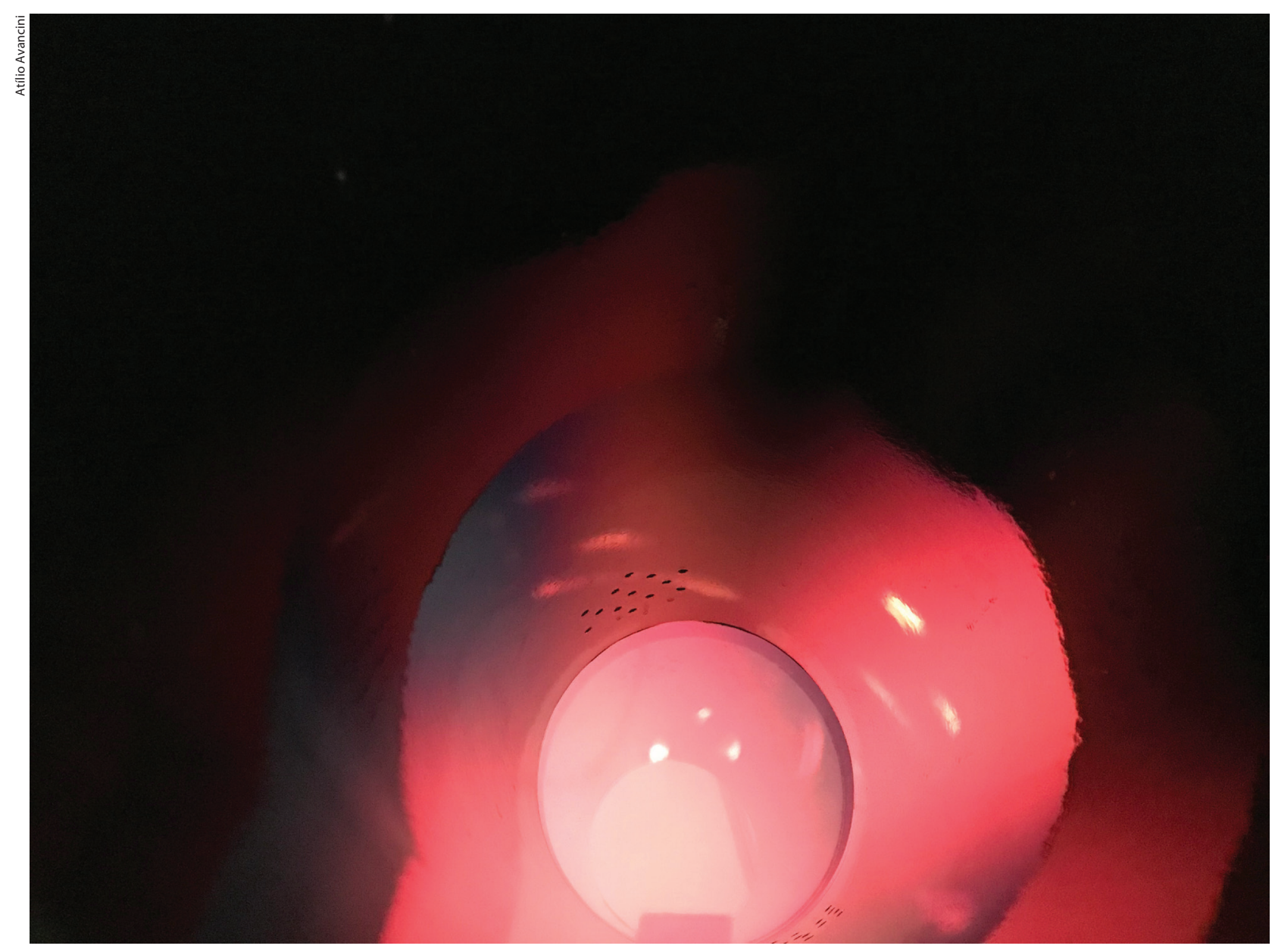

Infernus, 2008, madeira pintada, aparelho FVD, monitor e versão digital: encanto e sedução

O questionamento de Regina está sintetizado em outra obra intrigante. $\mathrm{O}$ visitante deve se curvar e espiar dentro de um tubo de madeira. Irá ver o Infernus, com sons borbulhantes e uma imagem que sugere uma rosa vermelha. Como todas as outras obras que marcam a sua trajetória, Infernus expressa o rigor estético e sempre questionador da artista. 